\title{
Oral Health Literacy and COVID-19 Pandemic Anxiety and Concerns Among Iranian Orthodontic Patients
}

\author{
Mahdjoube Goldani Moghadam (D), Maryam Omidkhoda² (D) Hanieh Kazemi² (D)
}

'Department of Orthodontics, Faculty of Dentistry, Birjand University of Medical Sciences, Birjand, Iran

2Department of Orthodontics, School of Dentistry, Mashhad University of Medical Sciences, Mashhad, Iran

Cite this article as: Goldani Moghadam M, Omidkhoda M, Kazemi H. Oral health literacy and covid-19 pandemic anxiety and concerns among iranian orthodontic patients. Turk J Orthod. 2021; 34(2): 93-101.

Main Points

- Most of the participants in this study respected the quarantine recommendations.

- There was no significant difference between women and men except for the level to which they respect the quarantine measures.

- Most of the respondents had an adequate level of oral health literacy (OHL).

- Most of the respondents indicated that they were calm regarding the COVID-19 pandemic

- There was a significant association between the level of $\mathrm{OHL}$ and willingness to attend orthodontic treatment, concerns regarding the impact of the pandemic situation on orthodontic treatment, and the frequency of daily brushing.

- The greatest concern for most patients regarding the impact of the COVID-19 outbreak on their orthodontic treatment was the possibility of a delay in the completion of treatment.

\begin{abstract}
Objective: This study aims to evaluate the impact of the COVID-19 pandemic on orthodontic appointments, and the concerns and anxiety levels of orthodontic patients in Iran.

Methods: An anonymous 40-question questionnaire was sent online to the patients of private orthodontic clinics in 2 cities of Birjand, and Mashhad, capitals of Eastern provinces of Iran. Orthodontic patients of Mashhad dental school received the questionnaire as well. Descriptive statistics were reported, and the association between gender, oral health literacy (OHL), and adherence to orthodontic appointments and attendance, along with data on feeling, concern, and level of anxiety regarding quarantine/coronavirus pandemic were evaluated using the chi-square analysis.

Results: Three hundred twenty-four patients, with a mean age of 32.43 years, answered the questionnaire. Fifty-seven percent of participants said that they only left home for their daily requirements. Seventy-two percent of the participants reported feeling calm about the COVID-19 pandemic and its consequences. Most of the patients (74\%) said that they would attend their orthodontic appointment in case of urgency, and $41 \%$ of patients declared that their greatest concern was the probability of a delay in completion of treatment. Forty-five percent of patients had adequate $\mathrm{OHL}$. There was a significant association between $\mathrm{OHL}$ and willingness to attend orthodontic treatment, concerns regarding the impact of the pandemic on orthodontic treatment, and the frequency of daily teeth brushing.
\end{abstract}

Conclusion: Women respected the quarantine more than men. Patients with higher OHL were more willing to attend their appointments, but only in case of an emergency, due to the outbreak of COVID-19. Women were more concerned and had better oral hygiene behaviors.

Keywords: COVID-19, orthodontics, questionnaire

\section{INTRODUCTION}

The new coronavirus disease (COVID-19) arose beginning late December 2019, with severe pneumonia first in Wuhan, China, and then rapidly spreading to 200 countries, including Iran, by March 31, 2020. In late January, 
the state of the COVID-19 pandemic was confirmed by the WHO, and the disease was defined as a public health emergency, raising global concern. ${ }^{2}$ It was declared that more than $80 \%$ of patients are asymptomatic, and that fever, fatigue, dry cough, and acute respiratory distress syndrome are among the most common symptoms of disease. ${ }^{3}$ By March 31, 2020, Iran was among the top 10 countries with the highest number of COVID19 cases. $^{4}$

The COVID-19 pandemic caused the closure and cancellation of many public places and social activities, and in many countries, people were asked to stay home and respect home quarantine instructions. Coronavirus was primarily transmitted from bats and pangolins to humans, and then became widespread by interpersonal transmission through direct contact or indirectly from respiratory droplets, aerosols, or fecal-oral routes. ${ }^{5-9}$ The easy transmission of the virus through respiratory droplets, aerosols, and close contact places dentists and dental hygienists among the groups with a high risk of COVID-19 infection. ${ }^{10}$ Many dental offices were closed, and many are still closed due to the COVID-19 outbreak, limiting their activities to managing emergencies. Many orthodontic treatments are pending in line with this decision, and patients have not had an appointment for months. This unexpected break in dental treatments can potentially cause some problems and discomfort, especially for orthodontic patients. The results of a study conducted to evaluate the anxiety level of the general Iranian population during the COVID-19 outbreak showed that people who were more involved in following the corona-related news and people in the age range of 21-40 had a higher level of anxiety. ${ }^{11}$ It was found that there is a significant association between the feelings about the COVID-19 pandemic and dental appointment attendance among Brazilian dental patients. ${ }^{12}$ Females were found to be more concerned about the pandemic situation, quarantine, and consequences. ${ }^{13}$ Considering the lack of information about the impact of the pandemic on orthodontic treatment in Iran, this study aimed to evaluate orthodontic patients' stress and anxiety level regarding the COVID-19 pandemic, and the impact of this situation on their orthodontic treatment. We also assessed oral health literacy $(\mathrm{OHL})$, oral health behaviors, and the relationship between these parameters in a population of orthodontic patients in 2 eastern cities in Iran.

\section{METHODS}

An anonymous online questionnaire comprising 40 questions was used for data collection, including 6 questions asking about general information (age, gender, city/state, educational level, occupational status, family size), 8 questions evaluating the perceived anxiety and concerns regarding the COVID-19 pandemic (the levels of anxiety about the coronavirus pandemic and the impact of quarantine on orthodontic treatment were evaluated by a numerical rating scale (NRS)), the impact of this pandemic on the participants' orthodontic treatment and how they observe quarantine and protective measures, 16 questions to assess $\mathrm{OHL}$, 4 questions regarding oral health behaviors, and finally, 6 selfassessment questions regarding the state of their oral health and attendance to orthodontic appointments. ${ }^{13,18}$ The ethics committee approved the study protocol of Birjand University of Medical Sciences (IR.BUMS.REC.1399.138). We did not obtain informed consent from the participants because our questionnaire was anonymous and did not disturb their treatment process. The online questionnaire surveyed patients above 12 years old who were actively undergoing orthodontic treatment. The questionnaire was sent to patients of private orthodontic clinics in 2 cities, Birjand, and Mashhad, capitals of Eastern provinces of Iran. Orthodontic patients of Mashhad dental school received the questionnaire as well. The questionnaire was active for data gathering for 1 week. ${ }^{13}$

An anonymous online questionnaire comprising 40 questions was used for data collection, including 6 questions asking about general information (age, gender, city/state, educational level, occupational status, family size), 8 questions evaluating the perceived anxiety and concerns regarding the COVID-19 pandemic the levels of anxiety about the coronavirus pandemic and the impact of quarantine on orthodontic treatment were evaluated by a numerical rating scale (NRS)), the impact of this pandemic on the participants' orthodontic treatment and how they observe quarantine and protective measures, 16 questions to assess $\mathrm{OHL}, 4$ questions regarding oral health behaviors, and finally, 6 self-assessment questions regarding the state of their oral health and attendance to orthodontic appointments. ${ }^{13,14}$

Health literacy is defined as follows: "the degree to which individuals can obtain, process, and understand basic health information and services needed to make appropriate health decisions". ${ }^{15}$ In oral health context, literacy can be considered as the skills necessary for people to understand the causes of poor oral health, to learn and adopt fundamental aspects of positive oral self-care behaviors, to communicate with oral health care providers, to place their names on dental treatment waiting lists or organize appointments, to find their way to dental clinic, to fill out the necessary forms and to comply with any required regimes, including follow-up appointments and compliance with prescribed medication. ${ }^{16}$ This definition addresses functional oral health literacy, encompassing knowledge, as well as the ability to use that knowledge in making appropriate oral health-related decisions. Oral health literacy, in this definition, encompasses far more than reading; it involves writing, numeracy, speaking, listening, and "understanding the system". ${ }^{17}$

The ethics committee approved the study protocol of Birjand University of Medical Sciences (IR.BUMS.REC.1399.138). We did not obtain informed consent from the participants because our questionnaire was anonymous and did not disturb their treatment process. The online questionnaire surveyed patients bove 12 years old who were actively undergoing orthodontic treatment. The questionnaire was sent to patients of private orthodontic clinics in 2 cities Mashhad and Birjand, capitals of Eastern provinces of Iran. Orthodontic patients of Mashhad University Of Medical Sciences received the questionnaire as well. The questionnaire was active for data gathering for 1 week (13). 


\section{Statistical Analysis}

Using Cochran's Formula, and considering the total of 1800 patients of private orthodontic clinics in the 2 cities of Birjand, and Mashhad, capitals of Eastern provinces of Iran. Orthodontic patients of Mashhad dental school received the questionnaire as well, the standard error of $5 \%$ and $95 \%$ for confidence interval, the sample size was calculated to be at least 317 . Results were obtained and analyzed using descriptive statistics. A chi-square test was used to compare and analyze the results. The chi-square test was used to evaluate the association between gender, the feeling and concern, level of anxiety regarding the quarantine/ coronavirus pandemic, and adherence and attendance to regular appointments. Similarly, to evaluate the association between $\mathrm{OHL}$ and the variables mentioned above, the chi-square test was used. The Statistical Package for Social Sciences version 21.0 software (IBM Corp.; Armonk, NY, USA). The level of significance was set at 0.05 .

\section{RESULTS}

Six hundred twenty-one patients viewed the questionnaire, 52\% of them (324 people) completed it. The average response time was 187 seconds. Most of the respondents (97\%) answered utilizing mobile devices, and the rest of them used a computer to complete the questionnaire.

In total, 324 patients who were in the course of their fixed orthodontic treatments (75 males, 249 females) participated in the study. The mean age of participants was 32.43 years (minimum 12 years, maximum 53 years).

Considering observance of the suggested quarantine, $57 \%$ of participants said that they only left home for their daily requirements, $40 \%$ stayed home completely, and $3 \%$ said that they lived their usual life and did not respect the quarantine at all.

Sixty-three percent of patients said that they worked/studied at home during the quarantine. Regarding the COVID-19 pandemic and its consequences, $72 \%$ were calm, and $20 \%$ reported being anxious. We asked the patients to report their anxiety level regarding the impact of pandemic on their orthodontic treatment on a scale of $0-10$. We classified the scores into 3 levels: low (0-3), moderate (4-6), and high (7-10). The reported anxiety level of $55 \%$ of patients was moderate, and only $14 \%$ reported feeling highly anxious. Most of the patients (74\%) said that they would attend their orthodontic appointment if urgent, and $26 \%$ said they would attend their appointment regardless of the emergency.

Forty-one percent of the patients declared that their greatest concern regarding the impact of the COVID-19 pandemic on their orthodontic treatment was the probability of a delay in their treatment. The detailed results can be seen in the tables.

We used the oral health literacy-adult questionnaire (OHL-AQ). This questionnaire's validity and reliability for the Iranian population have been previously confirmed..$^{14,18}$ This questionnaire has 16 questions in 5 sections, and the scores are in the range of 0 to 16 . The scores are categorized and interpreted as inadequate (0-9), borderline (11-12), and adequate (13-16) OHL. Fortyfive percent of the participants in our study had adequate $\mathrm{OHL}$, $27 \%$ were borderline, and the $\mathrm{OHL}$ of $28 \%$ of the patients was inadequate. The descriptive statistics and chi-square test results comparing different variables are presented in Tables 1-4 and Figures 1-3.

\section{DISCUSSION}

The questionnaire for orthodontic patients was available online for 1 week from June 21 to 27, 2020. It was answered by $52 \%$ of the patients who received the questionnaire.

Totally, 324 patients who were in the course of their fixed orthodontic treatments (75 males, 249 females) participated in the study. As mentioned earlier, the minimum sample size for this study was calculated to be 317 responses. The sample size in this study was comparable to that of Cotrin et al., ${ }^{13}$ in which 354 patients were included. However, it was smaller in comparison with the sample size of Peloso's study ${ }^{12}$ with 595 participants. It seems that differences of this magnitude would not have a considerable impact on the results. The questionnaire was available for patients of private orthodontic clinics in 2 cities, Birjand and Mashhad, capitals of Eastern provinces of Iran. Orthodontic patients of Mashhad received the questionnaire as well, and it was active for about 1 week.

Seventy-seven percent of the participants were females, and $23 \%$ were males. The results showed that $63 \%$ of the respondents were studying/working at home during the outbreak of the COVID-19 pandemic, 40\% stayed home completely during the suggested quarantine, and $57 \%$ left home only for emergencies. The results of a study conducted on Brazilian dental patients by Peloso et al. ${ }^{12}$ revealed similar results. They found that $54.5 \%$ were working from home, and 78\% left home only for emergencies such as buying food or medicine.

It is well understood that for many reasons, the COVID-19 outbreak can cause anxiety and stress. ${ }^{11}$ In a study conducted to assess the general Iranian population's anxiety level, and it was found that women, people who were more involved in following COVID-19 related news, and people in the age range of 21-40 were more anxious. It was suggested to design and plan some psychosocial interventions to control the anxiety level of the aforementioned groups of people. ${ }^{11}$ There was no significant difference between males and females regarding the items except for the level of respect for the quarantine. Considering the nature of health services provided in a dental clinic, the transmission of the infection to dentists and patients is possible. Although there are guidelines recommended by the Centers for Disease Control and Prevention (CDC), the American Dental Association, and WHO for working safely in a dental clinic, there may be concerns in presenting at a dental clinic during the pandemic. Considering these concerns, many dental clinics were closed or provided only emergency services for the patients when newly diagnosed cases of the COVID-19 infection were rapidly increasing. However, it could 
Table 1. Descriptive statistics of study variables including frequency and percentage

\begin{tabular}{|c|c|c|c|}
\hline Variable & Answer & Frequency & (Percentage) \\
\hline \multirow[t]{2}{*}{ Gender } & Male & 75 & $(23 \%)$ \\
\hline & Female & 249 & $(77 \%)$ \\
\hline How are you observing the quarantine? & $\begin{array}{l}\text { Stay home as much as possible (leave } \\
\text { home for emergencies) }\end{array}$ & 186 & $(57 \%)$ \\
\hline \multirow[t]{3}{*}{ Are you working or studying? } & Yes, and I leave home for work/study & 94 & $(29 \%)$ \\
\hline & Yes, I work/study at home & 163 & $(50 \%)$ \\
\hline & No & 67 & $(21 \%)$ \\
\hline \multirow{2}{*}{$\begin{array}{l}\text { How can you describe yourself regarding the anxiety and stress } \\
\text { you are experiencing because of COVID-19 pandemic? }\end{array}$} & Calm & 232 & $(72 \%)$ \\
\hline & Anxious & 65 & $(20 \%)$ \\
\hline \multirow{3}{*}{$\begin{array}{l}\text { How can you describe your anxiety level regarding the COVID-19 } \\
\text { pandemic? }\end{array}$} & Low & 97 & $(30 \%)$ \\
\hline & Moderate & 171 & $(53 \%)$ \\
\hline & High & 56 & $(17 \%)$ \\
\hline \multirow[t]{3}{*}{ Would you attend your orthodontic appointments in this period? } & Yes & 84 & $(26 \%)$ \\
\hline & Only in the case of emergency & 240 & $(74 \%)$ \\
\hline & No & 0 & 0 \\
\hline \multirow{3}{*}{$\begin{array}{l}\text { What is your greatest concern regarding your orthodontic } \\
\text { treatment in this situation? }\end{array}$} & The treatment would become prolonged & 134 & $(41 \%)$ \\
\hline & The final result would be less than ideal & 74 & $(23 \%)$ \\
\hline & $\begin{array}{l}\text { The problem with my teeth would get } \\
\text { worse }\end{array}$ & 15 & $(5 \%)$ \\
\hline \multirow[t]{4}{*}{ How many times a day you brush your teeth? } & 2-3 times a day & 184 & $(57 \%)$ \\
\hline & Once a day & 124 & $(38 \%)$ \\
\hline & 2-3 times a week & 9 & $(3 \%)$ \\
\hline & Once a week & 7 & $(2 \%)$ \\
\hline \multirow[t]{5}{*}{ How many times a day you eat sugary snacks? } & 3 times or more & 42 & $(13 \%)$ \\
\hline & Twice a day & 74 & $(23 \%)$ \\
\hline & Once a day & 55 & $(17 \%)$ \\
\hline & Occasionally & 104 & $(32 \%)$ \\
\hline & Rarely & 49 & $(15 \%)$ \\
\hline \multirow[t]{7}{*}{ Have you ever smoked? } & No, never & 301 & $(93 \%)$ \\
\hline & I quit smoking & 5 & $(1.5 \%)$ \\
\hline & I smoke 1 cigarette a month & 4 & $(1 \%)$ \\
\hline & I smoke $2-3$ cigarettes a month & 3 & $(1 \%)$ \\
\hline & I smoke 2-3 cigarettes a week & 3 & $(1 \%)$ \\
\hline & I smoke 1 cigarette a day & 3 & $(1 \%)$ \\
\hline & I smoke 2-3 cigarettes a day & 5 & $(1.5 \%)$ \\
\hline \multirow{2}{*}{$\begin{array}{l}\text { How did you attend your orthodontic appointment before the } \\
\text { COVID-19 outbreak? }\end{array}$} & Regularly on monthly basis & 269 & $(83 \%)$ \\
\hline & Often on monthly basis & 41 & $(13 \%)$ \\
\hline
\end{tabular}


Table 2. Association between gender, feeling and concern, and level of anxiety regarding quarantine/coronavirus pandemic (Chi-square test)

\begin{tabular}{|c|c|c|c|c|}
\hline Variables & Answer & Males & Females & $P$ \\
\hline \multirow[t]{3}{*}{ How are you observing the quarantine? } & Stay home during the entire quarantine period & 15 & 113 & \multirow{3}{*}{$\begin{array}{l}X^{2}=24.727 \\
d f=2 \\
P=.000^{*}\end{array}$} \\
\hline & $\begin{array}{l}\text { Stay home as much as possible (leave home } \\
\text { for emergencies) }\end{array}$ & 53 & 133 & \\
\hline & Going out as before the outbreak & 7 & 3 & \\
\hline \multirow{4}{*}{$\begin{array}{l}\text { How can you describe yourself regarding the anxiety } \\
\text { and stress you are experiencing because of the } \\
\text { COVID-19 pandemic? }\end{array}$} & Calm & 58 & 174 & \multirow{4}{*}{$\begin{array}{l}X^{2}=2.482 \\
d f=4 \\
P=.647\end{array}$} \\
\hline & Anxious & 12 & 53 & \\
\hline & Panic & 0 & 4 & \\
\hline & Indifferent & 3 & 11 & \\
\hline \multirow{2}{*}{$\begin{array}{l}\text { How can you describe your anxiety level regarding } \\
\text { the COVID-19 pandemic? }\end{array}$} & Low & 28 & 69 & \multirow{2}{*}{$\begin{array}{l}X^{2}=3.388 \\
d f=3 \\
P=.336\end{array}$} \\
\hline & Moderate & 36 & 135 & \\
\hline $\begin{array}{l}\text { Would you attend your orthodontic appointments in } \\
\text { this period? }\end{array}$ & No & 0 & 0 & $\begin{array}{l}X^{2}=1.875 \\
d f=1 \\
P=.171\end{array}$ \\
\hline \multirow{5}{*}{$\begin{array}{l}\text { What is your greatest concern regarding your } \\
\text { orthodontic treatment in this situation? }\end{array}$} & The treatment would become prolonged & 27 & 107 & \multirow{5}{*}{$\begin{array}{l}X^{2}=5.220 \\
d f=4 \\
P=.265\end{array}$} \\
\hline & The final result would be less than ideal & 19 & 55 & \\
\hline & The problem with my teeth would get worse & 6 & 9 & \\
\hline & The probability of injuries to lips and cheeks & 5 & 29 & \\
\hline & I am not concerned & 18 & 49 & \\
\hline \multirow{3}{*}{$\begin{array}{l}\text { How do you describe the level of your anxiety } \\
\text { regarding the impact of COVID-19 pandemic and } \\
\text { quarantine on your treatment? }\end{array}$} & Low & 27 & 75 & \multirow{3}{*}{$\begin{array}{l}X^{2}=2.822 \\
d f=2 \\
P=.224\end{array}$} \\
\hline & Moderate & 33 & 100 & \\
\hline & High & 15 & 74 & \\
\hline
\end{tabular}

Table 3. Association bBetween adherence to regular appointment and the concern and level of anxiety regarding quarantine/coronavirus pandemic (Chi-square test)

\begin{tabular}{|c|c|c|c|c|}
\hline Variables & Answer & $\begin{array}{l}\text { Patients who attend their } \\
\text { orthodontic appointment } \\
\text { regularly }\end{array}$ & $\begin{array}{l}\text { Patients who fail to } \\
\text { attend on a regular } \\
\text { basis }\end{array}$ & $P$ \\
\hline \multirow{3}{*}{$\begin{array}{l}\text { How can you describe your anxiety level } \\
\text { regarding the COVID-19 pandemic? }\end{array}$} & Low & 31 & 66 & \multirow{3}{*}{$\begin{array}{l}X^{2}=3.680 \\
d f=2 \\
P=.159\end{array}$} \\
\hline & Moderate & 37 & 134 & \\
\hline & High & 16 & 40 & \\
\hline \multirow[t]{4}{*}{$\begin{array}{l}\text { What is your greatest concern regarding your } \\
\text { orthodontic treatment in this situation? }\end{array}$} & $\begin{array}{l}\text { The treatment would } \\
\text { become prolonged }\end{array}$ & 42 & 92 & \multirow{4}{*}{$\begin{array}{l}X^{2}=12.557 \\
d f=4 \\
P=.014^{*}\end{array}$} \\
\hline & $\begin{array}{l}\text { The final result would be } \\
\text { less than ideal }\end{array}$ & 11 & 63 & \\
\hline & $\begin{array}{l}\text { The problem with my } \\
\text { teeth would get worse }\end{array}$ & 7 & 8 & \\
\hline & $\begin{array}{l}\text { The probability of } \\
\text { injuries to lips and } \\
\text { cheeks }\end{array}$ & 5 & 29 & \\
\hline \multirow{2}{*}{$\begin{array}{l}\text { How do you describe the level of your anxiety } \\
\text { regarding the impact of COVID-19 pandemic } \\
\text { and quarantine on your treatment? }\end{array}$} & Moderate & 27 & 106 & \multirow{2}{*}{$\begin{array}{l}X^{2}=3.984 \\
d f=2 \\
P=.136\end{array}$} \\
\hline & High & 25 & 64 & \\
\hline
\end{tabular}


Table 4. Association between oral health literacy, gender, feeling, concern, and level of anxiety regarding quarantine/coronavirus pandemic (Chi-square test)

\section{Oral Health Literacy}

\section{Variable}

Gender

How are you observing the quarantine?

Are you working or studying?

\section{How can you describe your anxiety level \\ regarding the COVID-19 pandemic? \\ Would you attend your orthodontic appointments in this period? \\ What is your greatest concern regarding your orthodontic treatment in this} situation?

How do you describe the level of your anxiety regarding the impact of the COVID-19 pandemic and quarantine on your treatment?

How many times a day you brush your teeth?

How many times a day you eat sugary snacks?

Have you ever smoked?

How did you attend your orthodontic appointment before the COVID-19 outbreak?

\begin{tabular}{|c|c|c|c|}
\hline Inadequate & Borderline & Adequate & $P$ \\
\hline 27 & 16 & 32 & \multirow{2}{*}{$\begin{array}{l}X^{2}=3.491 \\
d f=2 \\
P=.175\end{array}$} \\
\hline 64 & 72 & 113 & \\
\hline 32 & 30 & 66 & \multirow{2}{*}{$\begin{array}{l}X^{2}=6.082 \\
d f=4 \\
P=.193\end{array}$} \\
\hline 54 & 56 & 76 & \\
\hline 5 & 2 & 3 & \\
\hline 25 & 23 & 46 & \multirow{3}{*}{$\begin{array}{l}X^{2}=2.334 \\
d f=4 \\
P=.674\end{array}$} \\
\hline 44 & 45 & 74 & \\
\hline 22 & 20 & 25 & \\
\hline 63 & 64 & 105 & \multirow{5}{*}{$\begin{array}{l}X^{2}=10.736 \\
d f=8 \\
P=.217\end{array}$} \\
\hline 16 & 16 & 33 & \\
\hline 2 & 4 & 3 & \\
\hline 3 & 1 & 0 & \\
\hline 7 & 3 & 4 & \\
\hline 31 & 30 & 36 & \multirow{3}{*}{$\begin{array}{l}X^{2}=4.346 \\
d f=4 \\
P=.361\end{array}$} \\
\hline 45 & 41 & 85 & \\
\hline 15 & 17 & 24 & \\
\hline 34 & 25 & 25 & \multirow{3}{*}{$\begin{array}{l}X^{2}=12.175 \\
d f=2 \\
P=.002^{*}\end{array}$} \\
\hline 57 & 63 & 120 & \\
\hline 0 & 0 & 0 & \\
\hline 43 & 32 & 59 & \multirow{5}{*}{$\begin{array}{l}X^{2}=17.606 \\
d f=8 \\
P=.024^{*}\end{array}$} \\
\hline 16 & 19 & 39 & \\
\hline 6 & 6 & 3 & \\
\hline 10 & 4 & 20 & \\
\hline 16 & 27 & 24 & \\
\hline 30 & 26 & 46 & \multirow{3}{*}{$\begin{array}{l}X^{2}=6.530 \\
d f=4 \\
P=.163\end{array}$} \\
\hline 29 & 37 & 67 & \\
\hline 32 & 25 & 32 & \\
\hline 50 & 51 & 83 & \multirow{4}{*}{$\begin{array}{l}X^{2}=22.408 \\
d f=8 \\
P=.004^{*}\end{array}$} \\
\hline 31 & 35 & 58 & \\
\hline 8 & 1 & 0 & \\
\hline 2 & 1 & 4 & \\
\hline 9 & 12 & 21 & \multirow{5}{*}{$\begin{array}{l}X^{2}=11.269 \\
d f=8 \\
P=.187\end{array}$} \\
\hline 15 & 21 & 38 & \\
\hline 20 & 10 & 25 & \\
\hline 32 & 35 & 37 & \\
\hline 15 & 10 & 24 & \\
\hline 84 & 81 & 136 & \multirow{7}{*}{$\begin{array}{l}X^{2}=11.068 \\
d f=12 \\
P=.523\end{array}$} \\
\hline 0 & 3 & 2 & \\
\hline 1 & 1 & 2 & \\
\hline 2 & 1 & 0 & \\
\hline 1 & 0 & 2 & \\
\hline 2 & 1 & 0 & \\
\hline 1 & 1 & 3 & \\
\hline 78 & 69 & 122 & \multirow{3}{*}{$\begin{array}{l}X^{2}=3.195 \\
d f=6 \\
P=.784\end{array}$} \\
\hline 10 & 14 & 17 & \\
\hline 3 & 5 & 6 & \\
\hline
\end{tabular}


WHICH OF THE FOLLOWING ITEMS DO YOU CONSIDER IMPORTANT WHEN PRESENTING A DENTAL OFFICE IN THE PANDEMIC

SITUATION? (MORE THAN ONE OPTION WAS ACCEPATBLE) having access to disinfecting agents

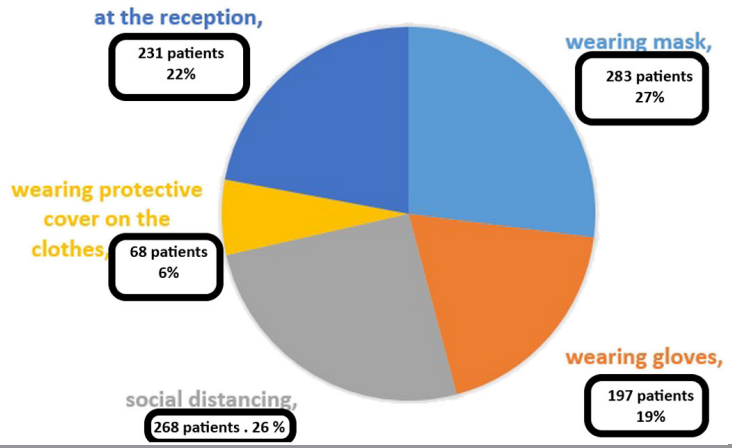

Figure 1. Descriptive statistics, including the percentage of patient's answers to "which of the following items do you consider important when presenting at a dental clinic in the pandemic situation?"

\section{WHAT ARE THE ORAL HEALTH RELATED INFORMATION SOURCES YOU USUALLY USE?}

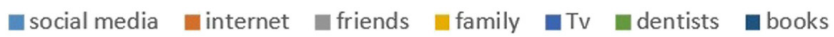

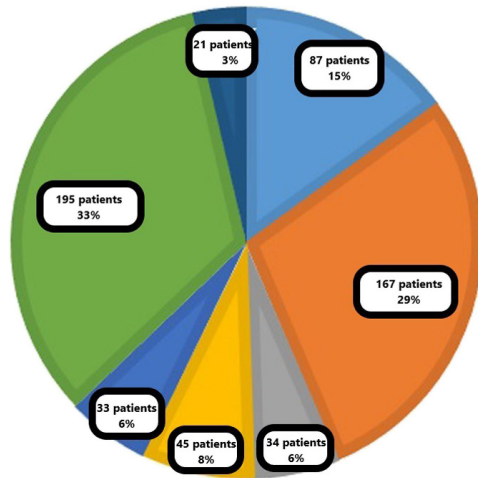

Figure 2. Descriptive statistics including the source percentage of patients' oral health-related information.

\section{HOW DO YOU DESCRIBE YOUR ORAL HEALTH?}

घery good $\square$ good $\square$ bad $\square$ very bad $\square$ no idea $\square$ not good, not bad

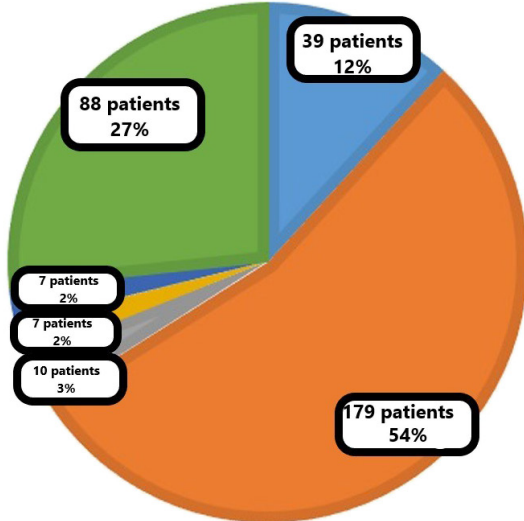

Figure 3. Descriptive statistics including patient's descriptions of their oral health. not be the case for ongoing active treatments such as orthodontic treatment. The orthodontic patient might have some extra concerns due to the unpredicted pause in their treatment and its possible consequences. Therefore, we asked them to describe their anxiety level in general and express how they felt that the pandemic would affect their orthodontic treatment. Most (72\%) of orthodontic patients who participated in our study said that they were calm, 55\% assessed their anxiety level as moderate, and $74 \%$ said that they would go for an orthodontic appointment if it was needed. The greatest concern among 52\% of our patients was the probability of a delay in completing their treatment, and $41 \%$ were moderately concerned about the pandemic's impact on their orthodontic treatment. There was no significant difference between males and females regarding the items except for the level they respect the quarantine. Xin Xiong et al., in a study conducted to assess mental distress in orthodontic patients during the COVID-19 pandemic, also found that disruption of routine appointments led to higher odds of mental distress and anxiety about treatment duration and outcome among orthodontic patients.

In Peloso et al. ${ }^{12}$ study, most patients were not calm regarding the situation, $28.6 \%$ were anxious, and $23.2 \%$ were scared. However, that study was conducted at an early stage of the pandemic in Brazil; the high level of anxiety among Brazilian dental patients was attributed to the reports circulated worldwide regarding the seriousness of the situation. ${ }^{12}$ Our study was conducted in late June 2020 when the pandemic had become a kind of chronic health problem, which can explain a lower anxiety level among our patients. Cotrin et al., ${ }^{13}$ in a study conducted to evaluate the impact of coronavirus pandemic on appointments and the anxiety/concerns of Brazilian orthodontic patients, revealed that $44.7 \%$ of respondents were calm regarding the coronavirus outbreak, and $46.3 \%$ were afraid or anxious. In that study, men were significantly calmer compared to women, which is contrary to our findings since we fail to find any significant difference between males and females in this regard. A nationwide survey of Chinese people to evaluate psychological stress caused by the COVID-19 pandemic further confirms what Cotrin et al. ${ }^{13}$ found. That survey showed that females were significantly more distressed than males. As previously mentioned, in a study aimed at evaluating the general Iranian population's anxiety level during the COVID-19 outbreak, the level of anxiety was higher among the women. ${ }^{11}$ Also, Xin Xiong et al. showed that female patients were more likely to experience mental distress during the pandemic, which might be attributed to the biological nature of their responses to stressors and risk factors, as well as their lower quality of life due to their orthodontic condition and treatment.

An interesting finding of the present study was the significant association between adherence to regular orthodontic appointment attendance and concerns regarding treatment. Those patients who attended their appointments regularly every month were significantly less concerned about the impact of pandemic on their treatment. Most of the respondents (74\%) said that they would go to the orthodontic appointment if it was needed. In the Cotrin et al. ${ }^{13}$ study, $60.2 \%$ of the participants answered positively to the question. The greatest concern 
of patients in both studies was a delay in completing the orthodontic treatment. A delay in treatment is probable since missed appointments increase the duration of orthodontic treatment.

We assessed the $\mathrm{OHL}$ of respondents as well. $\mathrm{OHL}$ has been defined by the American Dental Association as the ability to obtain, process, and understand basic health information. It was found that people with lower levels of OHL had poorer oral health status. Improving patients' $\mathrm{OHL}$ was found to be linked to better adherence to medical instructions, self-management skills, and overall treatment outcomes. Inadequate $\mathrm{OHL}$ of parents was associated with a high rate of dental caries and fewer fillings in their children. The findings of our study showed that $45 \%$ of patients had adequate $\mathrm{OHL}$, and only $28 \%$ of respondents had inadequate $\mathrm{OHL}$. OHL was significantly associated with the willingness of patients to attend their appointments in the pandemic situation. Patients with higher OHL levels were more likely to attend the orthodontic appointment only in the case of an emergency. Those with adequate $\mathrm{OHL}$ were more concerned about the impact of the COVID-19 outbreak on their orthodontic treatment and also significantly increased the frequency and duration of daily tooth brushing. These findings correlate with better adherence to medical and health instructions by people with higher $\mathrm{OHL}$.

Observing the social distancing instructions and wearing a mask were 2 of the measures which our respondents considered most important when visiting a dental clinic. Most of them used the internet as the main source to gather health information.

The nature of orthodontic treatment needs regular monthly appointments, which might be a challenge in situations like the present due to the COVID-19 pandemic. Improving patients OHL, following the responsible authorities' instructions, and making some modifications in orthodontic treatment plan to reduce the treatment time may help in this regard.

\section{CONCLUSION}

The results of this study showed that women respect the quarantine more than men. Most of the respondents indicated that they were calm regarding the COVID-19 pandemic. Patients who had more adherence to orthodontic appointment attendance (before the COVID-19 outbreak) were less concerned about their impact on their treatment. The greatest concern of our patients was the probability of a delay in completing their treatment. Most of the respondents had adequate OHL. Patients with higher OHL were more willing to attend the appointments only in the case of an emergency during the COVID-19 outbreak; they were more concerned about the impact of the COVID-19 outbreak on their orthodontic treatment and had better oral hygiene behaviors.

Ethics Committee Approval: This study was approved by Ethics committee of Birjand University of Medical Sciences (IR.BUMS.REC.1399.138).

Informed Consent: Verbal informed consent was obtained from the patients who agreed to take part in the study.
Peer Review: Externally peer-reviewed.

Author Contributions: Supervision - M.G.M., M.O.; Design - M.G.M.; Concept - M.G.M.; Resources - M.G.M., H.K.; Materials - M.G.M., M.O., H.K.; Data Collection and/or Processing - M.G.M., M.O., H.K.; Analysis and/or Interpretation - M.G.M., H.K.; Literature Search - M.G.M., H.K.; Writing Manuscript M.G.M., H.K.; Critical Review -H.K.

Conflict of Interest: The authors have no conflict of interest to declare.

Financial Disclosure: The authors declared that this study has received no financial support.

\section{REFERENCES}

1. Zhu N, Zhang $D$, Wang $W$ et al. A novel coronavirus from patients with pneumonia in China, 2019. N Engl J Med. 2020;382(8):727-733. [CrossRef]

2. Wong J, Goh QY, Tan Z et al. Preparing for a COVID-19 pandemic: a review of operating room outbreak response measures in a large tertiary hospital in Singapore. Can. Can J Anaesth. 2020;67(6):732745. [CrossRef]

3. Huang C, Wang Y, Li X et al. Clinical features of patients infected with 2019 novel coronavirus in Wuhan, China. Lancet. 2020;395(10223):497-506. [CrossRef]

4. Worldometer. Countries where COVID-19 has spread. 2020. Available at: [CrossRef].

5. Chan JF, Yuan S, Kok KH et al. A familial cluster of pneumonia associated with the 2019 novel coronavirus indicating person-to-person transmission:a study of a family cluster. Lancet.2020;395(10223):514523. [CrossRef]

6. Lam TT, Jia N, Zhang YW et al. Identifying SARS-CoV-2-related coronaviruses in Malayan pangolins. Nature. 2020;583(7815):282-285. [CrossRef].

7. Peng X, Xu X, Li Y et al. Transmission routes of 2019-nCoV and controls in dental practice. Int J Oral Sci. 2020;12(1):9. [CrossRef]

8. $\mathrm{Xu} \mathrm{H}$, Zhong $\mathrm{L}$, Deng J et al. High expression of ACE2 receptor of 2019-nCoV on the epithelial cells of oral mucosa. Int J Oral Sci. 2020;12(1):8. [CrossRef]

9. Lu CW, Liu XF, Jia ZF. nCoV transmission through the ocular surface must not be ignored. Lancet. 2019-;2020(10224); 395(10224):39.

10. Zhou W, Zhong N. The Coronavirus Prevention Handbook: 101 science-based tips that could save your life. Simon and Schuster; 2020.

11. Moghanibashi-Mansourieh A. Assessing the anxiety level of Iranian general population during COVID-19 outbreak. Asian J Psychiatr. 2020;51:102076. [CrossRef]

12. Peloso RM, Pini NIP, SUNDFELD NETO D et al. How does the quarantine resulting from COVID-19 impact dental appointments and patient anxiety levels? Braz Oral Res. 2020;34:e84. [CrossRef]

13. Cotrin PP, Peloso RM, Oliveira RC et al. Impact of coronavirus pandemic in appointments and anxiety/concerns of patients regarding orthodontic treatment. Orthod Craniofac Res. 2020;23(4):455-461. [CrossRef]

14. Naghibi Sistani MM, Montazeri A, Yazdani R, Murtomaa H. New oral health literacy instrument for public health: development and pilot testing. J Investig Clin Dent. 2014;5(4):313-321. [CrossRef]

15. Ratzan SC, Parker R. National Library of Medicine Current Bibliographies in Medicine: Health Literacy. Bethesda MD, National Institutes of Health; 2000:5-7.

16. Jackson RD, Eckert GJ. Health literacy in an adult dental research population: A pilot study. J Public Health Dent. 2008;68(4):196-200. [CrossRef]

17. Rudd R. Objective 11-2. Improvement of health literacy. In: Communicating Health: Priorities and Strategies for Progress. Washington DC, United States Department of Health and Human Services; 2003:35-60. 
18. Flynn PM, John MT, Naik A et al. Psychometric properties of the English version of the Oral Health Literacy Adults QuestionnaireOHL-AQ. Community Dent Health. 2016;33(4):274-280. [CrossRef]

19. World Health Organization. Clinical management of severe acute respiratory infection when COVID-19 is suspected. World Health Organization 2020. Available at: [CrossRef]. Accessed March 13 2020.

20. Xiong $X$, Wu $Y$, Fang $X$ et al. Mental distress in orthodontic patients during the coronavirus disease 2019 pandemic. Am J Orthod Dentofacial Orthop. 2020;158(6):824-833.e1. [CrossRef] [Epub ahead of print].
21. Qiu J, Shen B, Zhao M et al. A nationwide survey of psychological distress among Chinese people in the COVID-19 epidemic: implications and policy recommendations. GenPsychiatr.2020;33(2):e100213. [CrossRef]

22. Beckwith FR, Ackerman RJ, Jr, Cobb CM, Tira DE. An evaluation of factors affecting duration of orthodontic treatment. Am J Orthod Dentofacial Orthop. 1999;115(4):439-447. [CrossRef]

23. Baskaradoss JK. Relationship between oral health literacy and oral health status . BMC Oral Health. 2018;18(1):172. [CrossRef]

24. Khodadadi E, Niknahad A, Sistani MM, Motallebnejad M. Parents' oral health literacy and its impact on their children's dental health status. Electron Physician. 2016;8(12):3421-3425. [CrossRef] 